\title{
obituary
}

\section{Dennis Gabor, 1900-1979}

DENNIS GABOR, who received the Nobel Prize for Physics in 1972, for the invention of holography, died on 9 February 1979. One can surmise that he would have approved of such a one-sentence summary - holography was the crowning achievement, contemplated with great pleasure. Yet, it gives a distorting emphasis on a man who contributed radically new ideas to a number of quite distinct areas of applied physics, and who moved with effortless facility across the cultural divide.

Gabor was born 'in 1900 in Budapest, where he spent all his school days and completed three years at the Technical University. At the age of 21 , he moved to the Technische Hochschule in Berlin, where, after receiving his Diploma, he commenced his doctorate studies under Professor Mathias. These centered on the use of cathode ray tubes for the observations of transient waveforms thereby initiating a development, which has continued to this day, always in pursuit of the faster transients that have marked the path of progress in electronics. A byproduct of this research was the development of the first electron lens; it had been known for some time that electrons could be focused by means of a 'concentrating coil', but it was Gabor's use of a magnetic circuit to concentrate the magnetic field over a short region which led to the first practical lens. Although he did not, at the time, fully understand its mode of action (it was just before the celebrated paper by Busch which marks the beginnings of modern electron optics), the invention was to play an important role in the realisation of the first electron microscope. In fact, the first demonstration of such a microscope by Borries and Ruska used the actual lens created by Gabor.

Gabor had himself speculated on the possibility of realising an electron microscope, as he has recounted in a fascinating article on the History of the Invention of the Electronmicroscope (Elektrotech. Z. Ausg. A. 78, no. 15, $522-30,1957)$ - but enthusiasm for undertaking the development was dampened by the expectation that any objects of interest would be rapidly carbonized by the electron beam. By the time Borries and Ruska embarked on the venture, Gabor had moved to the Siemens

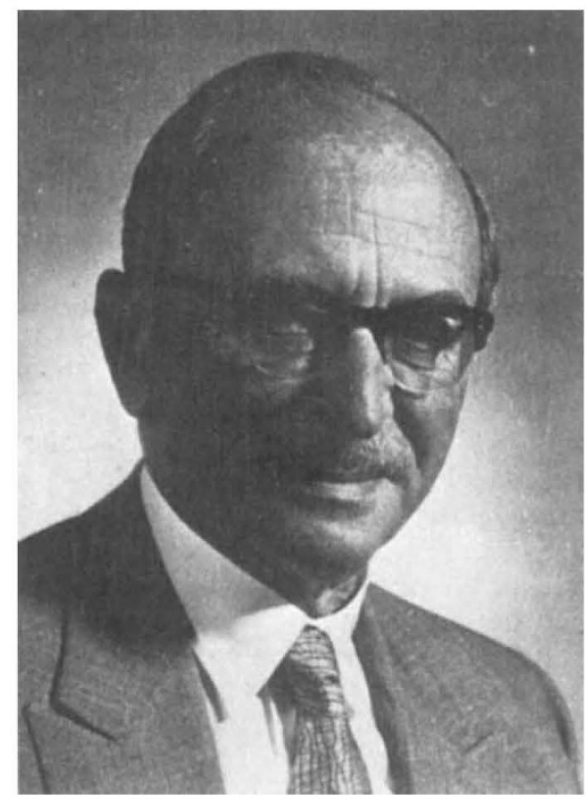

to the main stream of research - it was a time when the damning fact of foreign origin was more than a match for rational assessment. He was, nonetheless, able to make pioneering contributions to infra-red imaging and to develop a deeper understanding of the interaction between electrons and electromagnetic fields, the latter leading to a series of classic papers published in the last two years of the war. It also enabled him to continue work on electron optics and, above all, to do battle with what he perceived as the key problem - how to improve the quality of electron optical lenses. The constraints imposed by Laplace's equation deprive the electron optical designer of most of the weapons which are available in classical optics. The aberrations of electron optical lenses seemed to bar the path to the achievement of the ultra high resolution of which electron microscopes should have been capable - a resolution which could image single atoms.

Gabor tried to find room for manoeuvre

Research Laboratory.

It was a narrow escape from greatness at an early age. Perhaps that early disappointment served to sharpen his subsequent enthusiasm for the inventive process; Shockley has attributed his invention of the junction transistor to his chagrin at having missed the earlier pointcontact device.

The work at Siemens was largely devoted to a new type of gas discharge lamp. Whilst this research failed to lead to a commercially exploitable product, it marked the beginning of a life-long interest in the plasma state and its applications. It also led to a move to the Central Research Laboratories of B.T.H., Rugby, in $1933-$ Gabor's response to the election of Adolf Hitler in Germany. The move to Rugby was facilitated by inspired talent-spotting on the part of Professor T. E. Allibone.

While continuing his work on gas discharge lamps, Gabor never entirely abandoned his interest in electron optics. $\mathrm{He}$ invented what we would now call a mechanical analogue computer for electron trajectory tracing; coincidentally with Irving Langmuir, he discovered the basic limitations on electron density in electron optical systems.

During the war, by reason of his status as an alien, Gabor was not able to contribute by suggesting the introduction of space charge into lenses, to correct the aberrations - a technique which, as it eventually turned out, could not be effective, on account of the blurring occasioned by direct electron-electron interaction. Then, in 1947, quite suddenly, he perceived that the way to deal with bad lenses was not to strive to make them a little better, but, rather, to get rid of them altogether. The strategy envisaged by Gabor was made up of a number of quite distinct and quite brilliant insights - the ability to record the phase of a wavefront using materials sensitive only to intensity, by including a 'reference' wave; the possibility of recovering the information contained in the original wave by a reconstruction process with another, complementary wave; the recognition that the recording and reconstruction waves need not have the same wavelength - that an electron 'hologram' might be reconstructed at optical wavelengths. Gabor was able to demonstrate the principle at optical wavelengths, using the most coherent source then available - a mercury arc illuminating a pin hole. He published the results in a celebrated communication to Nature in 1948. It was a long way from the bold scheme envisaged for improving electron micrographs; 
indeed, to this day, such improvements have not been realised - though the hope of eventual success is not dead.

Gabor then developed a comprehensive theory of holography, but few more experiments were conducted for a dozen years. It was not until the invention of the laser provided experimenters with highly coherent sources that holography had its second birth, in a series of inspired researches undertaken by Leith and Upatnieks.

The subsequent story of holography is one of explosive growth. It is now the basis of a large and growing industry; it has inspired new forms of art. It is still far too early to assess its ultimate impact on science, technology and the conduct of human affairs.

How should such a discovery be weighed and judged? Gabor, himself, wondered how one should assess the value of a discovery in applied science, in the aforementioned paper on the history of the electron microscope. The following is a translation from the German of one of the opening paragraphs in that paper:

'It is hardly to be debated that those whose work is most highly regarded are those who have pioneered a new field which has subsequently been shown to be fertile. In this there is an element of luck, possibly even of injustice; honours are not bestowed - as they are, for example in mathematics - in proportion to the mental effort required to reach the result. In fact, I would go further and suggest that if a scientific achievement is to receive the highest accolade, it should not be wholly rational; there must be some element of boldness and risk. We regard the discovery of electromagnetic waves by Hertz as a greater achievement than Hamilton's theory of conical refraction not only because Hamilton's work put the finishing touch to the theory of crystal optics whilst in contrast, Hertz opened up a wide and new field, but also because, when Hertz began his classic investigations, Maxwell's theory was by no means established; moreover, there was not the slightest ground for the expectation that the conductivity of the electric spark could decay in $10^{-9}$ seconds. This was a matter of boldness and risk - not one of logical expectation.'

The passage was written with reference to electron microscopy. It was 1957 , and Gabor certainly had not the slightest expectation that holography could ever be viewed in such terms. Certainly, the research students he acquired when he moved to Imperial College as a Reader in 1948 - and these remarks are written from the vantage point of one of these regarded holography as ia laboratory curiosity. Yet, with hindsight, the passage is, surely, an entirely apt commentary on the invention of holography.

Often one finds that an inventive step follows very hard on the heels of another discovery, or some advance in technology which made it possible. Holography, however, was ready for birth at least half a century before the idea occurred to Gabor. Moreover, although the demonstrations in optics were difficult, there was no inherent reason why the principle should not have been demonstrated in acoustics - where, indeed, it has found application in recent years. By this criterion also, the invention of holography must be seen as an extraordinary stroke of brilliance.

In this period, Gabor also produced his pioneering contributions to what we now call communications theory - beginning with a remarkable paper published in the Journal of the Institution of Electrical Engineers in 1946. This work was inspired by the desire to gain a deeper understanding of the structure of information transmission; yet, included in the motivation there was, as always with his work, a thrust towards the applied, towards the inventive step. It led him to investigate means for transmission of information using 'band-width compression', a theme which remains an exciting area of research to this day.

When Gabor moved to Imperial College in 1948, he presented a remarkable and, at first, unfathomable phenomenon to his research students. He had little comprehension of the difficulty encountered by ordinary mortals in attempting to gain an appreciation of his aims in a particular research endeavour, or to follow a leaping thought line without the help of stepping stones. His lecture courses on electromagnetic theory, statistical physics, the plasma state, electron optics, seemed memorable but hardly capable of assimilation - at least, until the realisation dawned that they were not so much lectures as master classes. It was necessary to 'know' the subject before attending these occasions; but then the experience was enormously worthwhile - providing both the long historical view as insight in depth and generality. There must be many who still treasure the copious lecture notes typed at high speed by Gabor himself using an amazing two finger technique on a battered, ancient portable. There must be many who regret that these notes never found a more permanent expression in what would have amounted to a unique set of books; but research, invention and original thought was always the greater attraction and the more compelling master of his time.

There was no doubt amongst his students that Gabor could and should receive the Nobel Prize for something we debated just what it might be. Nor was this a symptom of hero worship, of which we were largely innocent. We could assess the magnitude of the intellect but found it harder to discern its direction. We were also aware of a personality of great warmth yet of inherent shyness. Communication was not always easy. And the attempts to capture that personality, the highly charged, penetrating comments, the humour, the perfection and elegance of expression, though clothed in a Hungarian accent of some substantial depth, was the supreme task of those endowed with any ability of mimicry - though one doubts whether their skill will ever again be displayed.

Recognition outside his immediate group was slow to come. Gabor was a physicist who saw himself as a practical engineer - a reversal of the more usual aspiration for role changing. Not all physicists recognised this situation. I remember a seminar, perhaps around 1953, to an audience largely of physicists, where Gabor discussed the interpretation of discrete energy losses suffered by electrons when transmitted through thin metal films, in terms of plasmon excitation - an explanation which we now know to be essentially correct. The criticisms which he met at the time were fierce, and seemed to transcend the requirements of scientific debate - there seemed to be an element of a demarcation dispute.

By the early fifties, Gabor had completed his work on holography, made pioneering contributions to information theory, to electron optics, to electronelectromagnetic interactions and to plasma theory. Yet, he was still a Reader in the University and repeatedly failed to achieve election to the Royal Society. The omission was resented by his students and others who knew him well; it was deeply felt by Gabor himself. It was hard to comprehend at the time; it is no easier to do so in retrospect. Throughout this period, however, Gabor's creative work never faltered. Flat television tube research involving the most ingenious electron optical conceptions lived side by side with learning machines, with holographic microscopy and, a little later, with schemes for direct generation of electricity from heat using a plasma - a technique which echoed some of his work on gas discharge lamps of three decades earlier. Many of these schemes remain as fascinating concepts, devoid of practical implementation. But it would be unwise to write them off; holography had a gestation period of 15 years.

In 1956, Gabor was, at long last, elected a Fellow of the Royal Society and two years later became the Professor of Applied Electron Physics at Imperial College. His inaugural address marked a totally new direction in his publications and his thought, - to the socio-political problems faced by mankind as the direct consequence of advances in technology. The lecture, later published in the form of a most compelling contribution to Encounter, eventually formed the basis of a celebrated book, Inventing the Future. The trilemma facing mankind: war, excess population and leisure, is now revealed wisdom - part of the backcloth of our existence. It was not so when the book was first published in 1963. The approach taken in this book - an appraisal of the 
enormous dangers, coupled with a guarded optimism that, with their recognition, the worst could be avoided - Gabor pursued and developed in a series of further publications. He became a founder member of the Club of Rome, and thereby became embroiled in the fierce debates which followed the publication of Limits to Growth by Forrester and Meadows. His stance was one of cheerful and total support for these authors - though a careful examination of his expressed opinions reveals that this support did not, in fact, rest on his assessment of the computer model calculations which caused such widespread alarm.

Just before Inventing the Future, it became clear that holography, transformed by the discovery of the laser, was turning into one of the most rapid

\section{Airey Neave}

A General Election is a deep parliamentary gulf dividing sharply one time from another. I have returned to the House of Commons not only to a new parliament and a new government but to unfamiliar faces that crowd the benches as solidly and confidently as did those whose places they have taken. But there is outstandingly one face absent from the chamber, one expected figure not again to be met in the long corridors. I refer to my friend Airey Neave, the victim of a cowardly political murder within the precincts of that same Palace of Westminster where we meet.

Leading figures in public life, the newspapers, radio and television have all said so much deservedly in tribute to $\mathrm{Mr}$ Neave, his life and work, that it might seem presumption on my part to add more. Nevertheless these columns give me an opportunity to enlarge a little on his considerable services to the Select Committee on Science and Technology of the House of Commons, for Airey Neave was a founder member of the committee from its establishment in 1967 until 1975 when he became opposition spokesman on Northern Ireland.

I was the first chairman of the select committee but in 1970 when the Conservative government of $\mathrm{Mr}$ Heath came to power, in accord with parliamentary practice, Airey Neave succeeded me for the parliamentary sessions of 1970-1974. Every chairman, I suppose, has his own style and Airey's was very much his own. In dealing with witnesses, especially those (and there are a few) who think that politicians cannot possibly have knowledge of anything except the suspect business of getting elected, he could be severe to near inquisitorial. Yet never for an instant did he go beyond the needs of the inquiry being conducted. As a good select committee chairman should, he saw his primary duty to parliament, not to governments or parties. I remember well how he gave a rising Conservative ministerial star caught out in a mistake a wigging that led to with- growth topics in applied science. The range of applications appeared to grow month by month; holography was recognised as a principle of such generality tht it could touch many branches of physics, biology and engineering. Gabor, himself, contributed several inventions to this growing field. He lectured widely on the subject. Many will never forget a brilliant discourse at the Royal Institution which he gave in 1969 . The recognition, so long denied, or belatedly bestowed, came in full flood. Honours of all kinds were showered upon him and, in 1972, the Nobel Prize.

There remained some good years. They were devoted to scientific work at the CBS Laboratories in the USA, to Imperial College and London, and to a villa in Italy. Gabor continued to contribute to what became his dominant and passionate

drawal and public apology. But to the general run of helpful and co-operative witnesses, enduring the unfamiliar ordeal of questioning in public, Airey was the soul of courtesy.

In the chair Airey Neave was vastly impressive to witnesses as he was to colleagues on the committee because of his detailed knowledge of the subject under consideration. His capacity for work was truly prodigious. Among the inquiries he handled either as chairman of the main committee or as chairman of a subcommittee, were population control, the Rothschild proposals and the computer industry.

But I suppose the inquiry that brings me closest to Airey Neave in memory was the one that the select committee carried out, through a sub-committee, into the choice to be made by Britain for the 'third generation' of nuclear reactors, the Magnox reactor being counted first generation and the advanced gas-cooled reactor second generation. This was during the time of the Heath government, when $\mathrm{Mr}$ Peter Walker was, as Secretary of State for Technology, the responsible minister.

The assumption had been that no firm decision would be taken on the choice to be made without a ministerial statement and the normal opportunity for parliamentary questioning. Then a long special article appeared in a leading Sunday newspaper by a science correspondent, to the effect that the Central Electricity Generating Board had made up its mind already and that American style pressurised water reactors were to be bought on a large scale for installation in the British electricity supply system, with the co-operation of our manufacturers and the apparent approval of the government.

Simple parliamentary questioning took us little further forward and Airey and I both agreed that this was just the kind of situation for which the select committee had been established.. After all, the British taxpayer had either spent or had guaranteed large sums of money in the past on the assumption that Britain had the most efficient and safest nuclear power arrange- concern - the adjustment of the human condition to the new world, which the explosive development in science and technology had wrought within his own lifetime and experience. Prophecy is the hardest of arts; scientists as a body are not notably more successful than others in its practice. Yet, if any doubt that there are some, a very few, who can penetrate that ultimate unknown at least some little distance, they should re-read Inventing the Future of 1963, or, perhaps, the Fawley Lecture of 1972, The proper priorities of Science and Technology.

Dennis Gabor married Marjorie, née Butler, in 1936, a marriage which brought great happiness and continuing support, in a life which knew both bitter disappointment as well as triumph and total fulfilment.

Eric A. Ash

ments in the world with the gas-cooled systems and now for parliament to be told that we had been wrong all the time took more than a little swallowing.

Because of his declared interest as a director of a plant manufacturer engaged in the nuclear field, Airey Neave felt he should not take the chairmanship of the inquiry and I occupied his place, though he served on the sub-committee. To a great extent it was the safety of the PWR in an emergency situation that took the attention of the inquiry and on this point critical evidence was received from Sir Alan Cottrell, then Chief Scientist to the government - evidence which had not been published before.

The conclusion of the select committee, reported to the House of Commons, was that the case for abandoning British reactor systems and adopting the American system could not be sustained by the evidence submitted and we advised caution over the PWR. Needless to say, some but not all parts of the nuclear technological establishment attacked the select committee for political meddling and worse. Nevertheless, a full day's debate in the Commons found members of parliament on both sides impressed by the committee's findings and Airey and I followed up the debate with a joint appearance on the national television network which engendered a large correspondence. Many of our correspondents were obviously impressed by the way in which a select committee of the Commons could, while supporting nuclear development in general, run up a danger flag about one particular proposed development. Who in the light of Harrisburg could to-day say we were wrong?

I spoke to Airey Neave last on the Thursday night before his death on the following day. We met by chance in the Commons lobby and discussed the future of the selectl committee on Science and Technology in the light of suggested procedural reforms for select committees in a new parliament. I did not know then I was never to see him again.

Arthur Palmer 